Article

\title{
Application of Polyacrylamide Flocculant for Stabilization of Anaerobic Digestion under Conditions of Excessive Accumulation of Volatile Fatty Acids
}

\author{
Anna A. Nikitina ${ }^{1}$, Artem A. Ermoshin ${ }^{1}$, Elena A. Zhuravleva ${ }^{1}$, Andrey A. Kovalev ${ }^{2}{ }^{\circledR}$, Dmitriy A. Kovalev ${ }^{2}$, \\ Vladimir Panchenko ${ }^{3}$ (D) and Yuri V. Litti ${ }^{1, *(D)}$ \\ 1 Federal Research Center "Fundamentals of Biotechnology" of the Russian Academy of Sciences, \\ 119071 Moscow, Russia; nikitina.anna.1989@mail.ru (A.A.N.); artem.ermshin@gmail.com (A.A.E.); \\ zhuravleva_2595@mail.ru (E.A.Z.) \\ 2 Federal Scientific Agroengineering Center VIM, 109428 Moscow, Russia; kovalev_ana@mail.ru (A.A.K.); \\ kovalev_da80@mail.ru (D.A.K.) \\ 3 Department of Theoretical and Applied Mechanics, Russian University of Transport, 127994 Moscow, Russia; \\ pancheska@mail.ru \\ * Correspondence: litty-yuriy@mail.ru; Tel.: +7-926-369-9243
}

check for

updates

Citation: Nikitina, A.A.; Ermoshin, A.A.; Zhuravleva, E.A.; Kovalev,

A.A.; Kovalev, D.A.; Panchenko, V.; Litti, Y.V. Application of

Polyacrylamide Flocculant for Stabilization of Anaerobic Digestion under Conditions of Excessive Accumulation of Volatile Fatty Acids. Appl. Sci. 2021, 11, 100. https:// dx.doi.org/10.3390/app11010100

Received: 30 November 2020 Accepted: 21 December 2020 Published: 24 December 2020

Publisher's Note: MDPI stays neutral with regard to jurisdictional claims in published maps and institutional affiliations.

Copyright: (c) 2020 by the authors. Licensee MDPI, Basel, Switzerland. This article is an open access article distributed under the terms and conditions of the Creative Commons Attribution (CC BY) license (https: / / creativecommons.org/ licenses/by/4.0/).
Featured Application: Here we establish a strategy for recovering the methanogenic activity in acidified reactors by PAM-forced flocculation.

\begin{abstract}
Excessive accumulation of volatile fatty acids (VFA) is one of the major factors destabilizing methanogenic digestion of organic wastes in anaerobic bioreactors. Existing methods of stabilization of this process are mostly expensive and labor-intensive, often requiring removal of a considerable portion of acidified biomass from the bioreactor. We propose a method for methanogenesis restoration in such soured reactors by the addition of a cationic polyacrylamide flocculant (PAM) at $20 \mathrm{mg} / \mathrm{g}$ total solids. After flocculant addition, mixing should be minimized to prolong the existence of the floccules formed in the presence of the flocculant. While partial microbial degradation of the polyacrylamide flocculant was observed during the thermophilic anaerobic process, complete PAM mineralization did not occur. Significant inhibition of anaerobic processes, primarily in the activity of syntrophic propionate-oxidizing bacteria, was observed at PAM concentrations above $40 \mathrm{mg} / \mathrm{g}$ total solids.
\end{abstract}

Keywords: anaerobic digestion; volatile fatty acids; polyacrylamide flocculant; acidification; methanogenesis; restoration

\section{Introduction}

Population growth leads to an increase in the amount of organic waste. The predicted worldwide amount of organic waste produced annually by 2025 exceeds $6 \times 10^{6} \mathrm{t}$ [1] Sewage sludge (SS) and municipal solid waste (MSW) are the main groups of municipal organic waste, with their production rates increasing, according to the recent estimates, by $2-4.5 \%$ per year [2]. Conversion of municipal organic waste using anaerobic digestion (AD) has become increasingly popular in recent years as a sustainable technology producing green energy $[3,4]$. In the course of $\mathrm{AD}$, organic matter is sequentially degraded to gaseous products $\left(\mathrm{CO}_{2}\right.$ and $\left.\mathrm{CH}_{4}\right)$ due to the activity of various functional and phylogenetic groups of microorganisms $[5,6]$. Increasing the substrate load and decreasing the moisture content of the treated waste are among the commonly used approaches to improve the operation rates of anaerobic digesters [4,7]. A too high organic load may, however, lead to excessive accumulation of volatile fatty acids (VFA), which is one of the major factors destabilizing the anaerobic digestion [8,9]. VFA are the key intermediates of organic matter decomposition, and the rate of their degradation is one of the factors determining the overall rate of the 
process. VFA produced by fermenting bacteria are then utilized by syntrophic bacteria and acetoclastic methanogens. The growth rates of both syntrophs and methanogens are lower than that of fermenting organisms. Therefore an excessive accumulation of VFA can suppress the activity of the whole microbial community and destabilize the anaerobic digestion $[5,6]$.

Development of approaches to overcome AD destabilization caused by excessive VFA accumulation is an important task for researchers and technologists.

Addition of alkaline reagents is a known approach used to restore methanogenesis in soured bioreactors [10]. Thus, doses of lime, sodium carbonate, sodium hydroxide, ammonium hydroxide, or gaseous ammonia may be added to neutralize the acids produced during fermentation. Application of lime is not desirable, since insoluble $\mathrm{CaCO}_{3}$ is formed, which is deposited in the pipes and on the reactor walls [6]. While ammonia and its compounds may be used for $\mathrm{pH}$ stabilization, they have a toxic effect on microorganisms and result in an additional nitrogen load in the anaerobic bioreactors [11]. Moreover, the addition of one or two portions of alkaline agents is inefficient, since increased $\mathrm{pH}$ results in rapid restoration of activity of hydrolytic and acidogenic microorganisms, accompanied by a still greater increase in VFA concentration (up to 14-15 g/L). Methanogenic archaea, with their growth rate and activity lower than those of the hydrolytic and acidogenic microorganisms, cannot cope with converting VFA to biogas [12]. To restore methanogenesis in the soured digester treating the organic fraction of MSW (OFMSW), an alkali and an additional source of the methanogenic microbial community, such as anaerobically digested sewage sludge or soil from the anaerobic zone of a landfill site, were added simultaneously [12]. While this method proved efficient in methanogenesis restoration, it implies a significant dilution of soured digesting mass in the limited reactor volume and requires the utilization of excessive soured biomass, which has a sharp unpleasant odor [12].

Microorganisms thriving as various biofilms are known to be more resistant to unfavorable conditions and biocidal factors than free-living cells. The close proximity between microorganisms within the biofilms also results in better microbial interactions and higher substrate conversation rates [5]. Biofilms are either formed on a carrier surface or develop naturally due to cell self-immobilization as granules and floccules without special carriers. Aggregation of suspended particles may be accelerated by the addition of various flocculants. Polyacrylamide flocculants are most often used in wastewater treatment and utilization of sewage sludge to improve the separation of the solid and liquid phases [13-15]. In our earlier experiments, different concentrations of the polyacrylamide cationic flocculant Praestol 650 (PAM) were used for SS thickening before batch-mode AD. At the non-optimal inoculumto-substrate ratio (ISR) (40/60), which led to AD destabilization, unexpected restoration of methanogenesis occurred in the soured mixture with elevated PAM content $(40 \mathrm{mg} / \mathrm{g}$ total solids), despite the inhibiting accumulation of volatile fatty acids (14-15 g/L) and pH drop (5.5) [16]. The possible application of flocculants for methanogenesis restoration in the bioreactors destabilized by excessive VFA accumulation has not been studied previously. It is known, however, that PAM may have a negative effect on methanogenesis due to the formation of large aggregates, which results in less efficient mass transfer $[13,16]$. Moreover, such products of PAM degradation under anoxic conditions as polyacrylic acid, acrylamide, and acrylic acid may have an inhibitory effect on microorganisms of the methanogenic community $[17,18]$. On the other hand, since PAM was shown to be degraded under anaerobic conditions, it may be used as an additional source of carbon and nitrogen and thus contribute to an increase in methane yield [17].

The present study is aimed at investigating biodegradability and toxicity of the polyacrylamide flocculant under anaerobic conditions and at testing the possibility of the application of PAM-enforced flocculation for stabilization of anaerobic digestion after excessive VFA accumulation. 


\section{Materials and Methods}

\subsection{Substrate and Inoculum}

A mixture of acetate, propionate, and butyrate was used as a substrate to evaluate the toxicity of PAM. Surplus activated sludge (SS) from Kuryanovo wastewater treatment facilities (Moscow, Russia) and simulated organic fraction of municipal solid waste (s-OFMSW) were used as substrates. Dry pet food (Chappi, Mars Petcare, Russia) was used to simulate the organic fraction of the MSW. Similar to OFMSW, dry pet food has a high content of easily degradable organic matter; it differs from OFMSW in its more homogeneous composition, which is important for laboratory experiments. Total solids (TS) content in surplus activated sludge and s-OFMSW was $13.4 \pm 0.1$ and $905.5 \pm 0.2 \mathrm{~g} / \mathrm{kg}$, respectively. Volatile solids (VS) content was $8.0 \pm 0.2$ and $846.8 \pm 0.9 \mathrm{~g} / \mathrm{kg}$ for surplus activated sludge and s-OFMSW, respectively. Thickened thermophilically digested sewage sludge from Kuryanovo wastewater treatment facilities was used as inoculum. TS and VS content in thickened thermophilically digested SS was $48.6 \pm 0.1$ and $20.5 \pm 0.1 \mathrm{~g} \mathrm{~kg}$, respectively.

The cationic polyacrylamide flocculant Praestol 650 (PAM) (Ashland, Germany), which is widely used in wastewater treatment plants in Russia, was used as a flocculant.

\subsection{Experimental Setup}

To investigate the biodegradability and toxicity of the PAM flocculant under anaerobic conditions, samples of thickened digested SS (3 g) were dispensed into $120 \mathrm{~mL}$ vials and supplemented with a liquid medium (mineral solution without sulfide and bicarbonate [19]) to $50 \mathrm{~mL}$. In the vials designated as " $\mathrm{T}$ " (for toxicity), a mixture of acetate, propionate, and butyrate $(60,10$, and $30 \mathrm{mM}$, respectively) was added as a substrate. The VFA ratio was selected based on previous experiments [12,16]. The samples with the medium without the additional substrates were designated " $\mathrm{B}$ " (for biodegradability). All samples were then supplemented with the PAM to the final concentrations of 0 (control samples), 5, 40, 80,200 , and $400 \mathrm{mg} / \mathrm{g}$ TS. To establish anaerobic conditions, the vials were purged with nitrogen and sealed with rubber stoppers and aluminum caps. The experiment was carried out for 40 days in accordance with Campos et al. [13].

The possible flocculant application to restore methanogenesis in the bioreactor destabilized by the accumulation of high VFA concentrations was studied in the next experiment. It was carried out in $500 \mathrm{~mL}$ vials with $100 \mathrm{~mL}$ of a digesting mixture in a batch mode. For the rapid accumulation of VFAs and inhibition of methanogenesis, the following were used:

- a low inoculum to substrate ratio (ISR $=30 \% / 70 \%$ on VS basis);

- a high proportion of readily degradable co-substrate, s-OFMSW, which was $45 \%$ of the total VS of the digesting mixture (a mixture of inoculum, co-substrates and tap water). Accordingly, the second co-substrate, namely SS, represented $25 \%$ of the total VS of the mixture;

- $\quad$ a high concentration of VS in the mixture $(40 \mathrm{~g} / \mathrm{kg})$.

All that resulted in the accumulation of excessive VFA, a pH decrease, and termination of methanogenesis. After 7 days, the vials were supplemented with a $1 \%$ water solution of the flocculant to the final concentrations of 20,40, and $60 \mathrm{mg}$ PAM/g TS. After addition of the PAM solution all vials were purged with nitrogen.

To achieve the same mixture volume and moisture content, relevant amounts of water were added to the control vials and those with 20 and $40 \mathrm{mg}$ PAM/g TS. Some vials were incubated under non-mixing conditions, while others were mixed (100 rpm).

All experiments were conducted under thermophilic conditions $\left(50 \pm 0.5^{\circ} \mathrm{C}\right)$.

\subsection{Analytical Methods}

The parameters monitored in all experiments were the composition of the gas phase $\left(\mathrm{CH}_{4}, \mathrm{CO}_{2}\right.$, and $\left.\mathrm{H}_{2}\right)$, liquid phase (VFA and alcohols), total ammonia nitrogen content (TAN), and $\mathrm{pH}$. Each time after taking liquid samples all vials were purged with nitrogen. TS and VS were determined at the beginning and end of the experiment. The measurements were carried out as described previously [16]. Composition of gas-phase was measured 
by gas chromatography. The amount of produced methane was calculated based on the concentration of methane in the gas phase of batch reactors, the gauge pressure and incubation temperature were taken into account [16].

The size of particles (floccules) in the mixture treated with different PAM concentrations was determined before and after digestion. Particle size distribution was determined on a Shimadzu SALD-2300 laser diffraction particle size analyzer (Kyoto, Japan). A small volume of the mixture was pumped through the measuring cell, and the size of solid particles was analyzed according to diffraction of the red laser radiation.

The standard options implemented in MS Excel were used for statistical analysis.

\section{Results}

3.1. Toxicity of the PAM and its Possible Degradation under Anaerobic Conditions

\subsubsection{Toxicity of the PAM}

Toxicity of the polyacrylamide flocculant for the microorganisms of the methanogenic community was determined using the mixture of simple substrates: acetate, propionate, and butyrate (series T). The tested PAM concentrations cover the range from the working concentrations used in wastewater treatment $(5 \mathrm{mg} / \mathrm{g}$ TS) to extremely high ones (200$400 \mathrm{mg} / \mathrm{g} \mathrm{TS}$ ), which may potentially have a significant inhibitory effect on methanogenesis. Experimental results are presented in Figure 1a and Table 1.
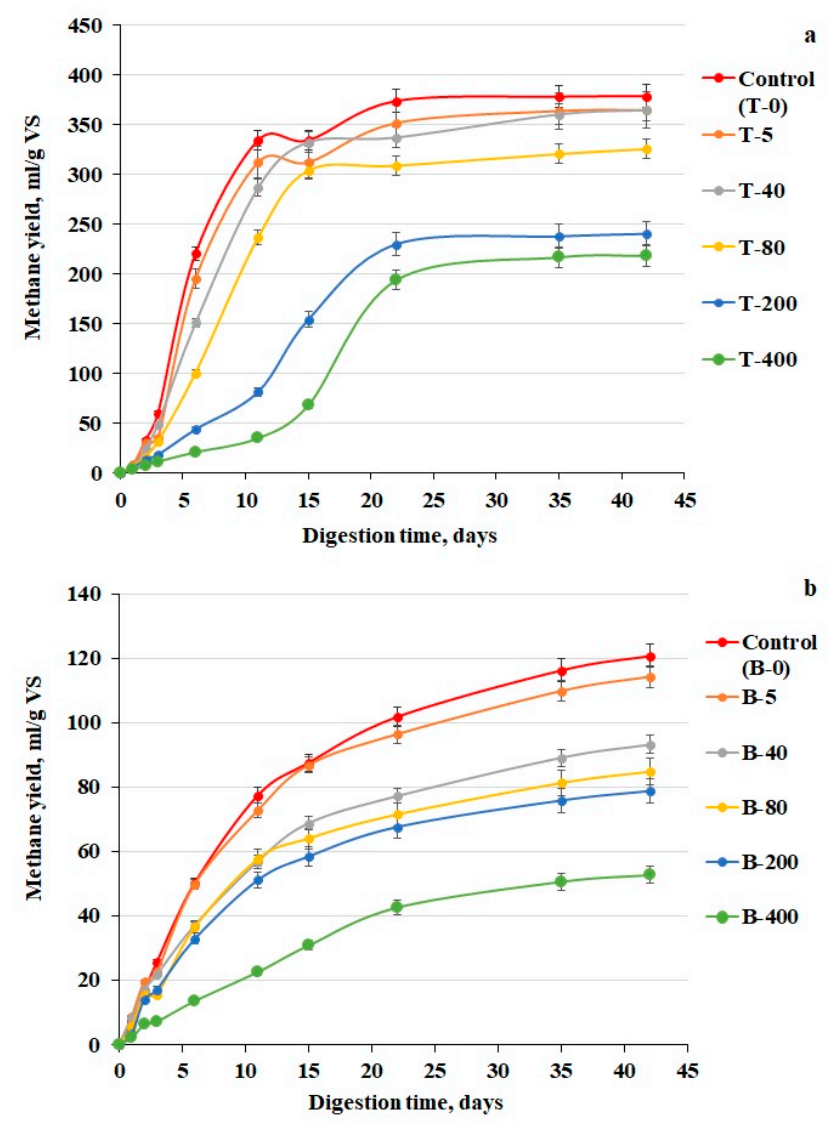

Figure 1. Dynamics of methane accumulation (ml/g volatile solids (VS) initial) in experiments on the determination of polyacrylamide (PAM) toxicity (a) and PAM biodegradability (b). Specific methane yield was calculated considering the organic matter of the PAM. 
Table 1. Characteristics of the process in the course of batch incubation of digested sludge with different concentrations of the polyacrylamide flocculant supplemented with volatile fatty acids (VFA) mixture as a substrate.

\begin{tabular}{|c|c|c|c|c|c|c|c|c|}
\hline \multirow[b]{2}{*}{ Sample } & \multirow{2}{*}{$\begin{array}{c}\text { Day of } \\
\text { Incubation }\end{array}$} & \multicolumn{4}{|c|}{ VFA Concentration } & \multirow{2}{*}{$\begin{array}{c}\text { Ammonium } \\
\text { Concentration, } \\
\mathrm{mg} / \mathrm{L}\end{array}$} & \multirow[b]{2}{*}{$\begin{array}{c}\text { Methane } \\
\text { Content, \% }\end{array}$} & \multirow{2}{*}{$\begin{array}{l}\text { Methane } \\
\text { Yield, mL }\end{array}$} \\
\hline & & $\begin{array}{l}\text { Acetate, } \\
\text { mmol/L }\end{array}$ & $\begin{array}{c}\text { Propionate, } \\
\mathrm{mmol} / \mathrm{L}\end{array}$ & $\begin{array}{l}\text { Butyrate, } \\
\mathrm{mmol} / \mathrm{L}\end{array}$ & $\begin{array}{l}\text { Total VFA, } \\
\text { g/L }\end{array}$ & & & \\
\hline \multirow{4}{*}{$\begin{array}{l}\text { Control } \\
\text { T-0 }\end{array}$} & 0 & 44.871 & 6.965 & 22.783 & 5.20 & 35.2 & 0 & 0 \\
\hline & 6 & 18.617 & 3.289 & 0.159 & 1.35 & 36.5 & 77.29 & 85.98 \\
\hline & 22 & 1.705 & 0.015 & 0.025 & 0.10 & - & 79.22 & 144.63 \\
\hline & 42 & 0.512 & 0.003 & 0.007 & 0.03 & 76.5 & 23.27 & 146.47 \\
\hline \multirow{4}{*}{$\mathrm{T}-5$} & 0 & 44.871 & 6.965 & 22.783 & 5.20 & 35.2 & 0 & 0 \\
\hline & 6 & 24.986 & 4.186 & 0.696 & 1.84 & 58.4 & 76.48 & 76.4 \\
\hline & 22 & 3.343 & 0.020 & 0.051 & 0.20 & - & 77.59 & 131.37 \\
\hline & 42 & 0.011 & 0.003 & 0.004 & 0 & 89.6 & 25.07 & 138.44 \\
\hline \multirow{4}{*}{$\mathrm{T}-40$} & 0 & 44.871 & 6.965 & 22.783 & 5.20 & 35.2 & 0 & 0 \\
\hline & 6 & 35.412 & 6.566 & 4.472 & 2.96 & 44.2 & 76.73 & 60.93 \\
\hline & 22 & 0.429 & 6.712 & 0.053 & 0.52 & - & 80.01 & 136.41 \\
\hline & 42 & 6.170 & 0.026 & 0.007 & 0.37 & 100.3 & 41.39 & 147.56 \\
\hline \multirow{4}{*}{$\mathrm{T}-80$} & 0 & 44.871 & 6.965 & 22.783 & 5.20 & 35.2 & 0 & 0 \\
\hline & 6 & 33.418 & 6.386 & 8.896 & 3.21 & 68.2 & 75.46 & 42.13 \\
\hline & 22 & 0.524 & 6.610 & 0.030 & 0.52 & - & 78.51 & 129.48 \\
\hline & 42 & 4.822 & 2.884 & 0.005 & 0.49 & 103.2 & 48.70 & 136.49 \\
\hline \multirow{4}{*}{$\mathrm{T}-200$} & 0 & 44.871 & 6.965 & 22.783 & 5.20 & 35.2 & 0 & 0 \\
\hline & 6 & 42.764 & 9.203 & 24.309 & 5.31 & 61.8 & 73.23 & 20.24 \\
\hline & 22 & 0.362 & 7.214 & 0.070 & 0.55 & - & 78.16 & 106.60 \\
\hline & 42 & 3.211 & 4.444 & 0.012 & 0.51 & 104.8 & 33.59 & 111.46 \\
\hline \multirow{4}{*}{$\mathrm{T}-400$} & 0 & 44.871 & 6.965 & 22.783 & 5.20 & 35.2 & 0 & 0 \\
\hline & 6 & 44.671 & 8.234 & 26.129 & 5.51 & 101.4 & 70.94 & 11.12 \\
\hline & 22 & 12.164 & 8.250 & 0.192 & 1.34 & - & 79.07 & 104.09 \\
\hline & 42 & 0.475 & 8.307 & 0.004 & 0.63 & 131.7 & 31.33 & 117.29 \\
\hline
\end{tabular}

VFA-volatile fatty acids.

Active methanogenesis in all samples continued for 22 days. According to the data presented in Figure 1a, the addition of the flocculant even at its minimal concentration $(5 \mathrm{mg} / \mathrm{g}$ TS) caused a decrease in the initial rate of methanogenesis. However, no inhibitory effect on anaerobic digestion was observed after 11 days of the experiment at flocculant concentrations of up to $40 \mathrm{mg} / \mathrm{g}$ TS. This finding was confirmed by the values of total methane yield which were similar to those of the control samples. PAM concentrations of up to $40 \mathrm{mg} / \mathrm{g}$ TS did not affect the final methane yield. In the T-400 series (400 mg PAM/g TS), the initial methanogenesis rate decreased significantly (by $76.5 \pm 2.4 \%$ ) compared to the control samples without PAM. However, intensification of methanogenesis was observed after 15 days of incubation. The methane yield at the end of the experiment was $57.6 \pm 1.9 \%$ of the yield in the control samples.

Importantly, the highest tested PAM concentration ( $400 \mathrm{mg} / \mathrm{g}$ TS), despite its pronounced inhibitory action, did not cause termination of methanogenesis when VFA were used as the substrate.

The VFA consumption rate and amount of consumed VFA varied depending on PAM concentration in the samples (Table 1). During the first 6 days of the experiment, $\sim 74 \%$ of the added substrates (considering the VFA formed during the decomposition of VS of inoculum) were consumed in the control samples. In the samples T-5, T-40, and T-80, the amounts of consumed substrates were $64.6,43.1$, and $38.3 \%$, respectively.

PAM was found to have an inhibitory effect on propionate degradation. After 42 days propionate was completely consumed only in the samples with PAM concentrations below $40 \mathrm{mg} / \mathrm{g}$ TS. Propionate consumption in the samples T- 80 and T-200 was 58.6 and 51.7\%, respectively. Propionate concentration in the sample T-400 did not change. Acetate concen- 
trations increased in T-40, T-80, and T-200 between days 22 and 42 of the experiment. It was associated with complete or partial propionate degradation. Partial inhibition of the acetate consumption was revealed in the samples with PAM concentrations above $40 \mathrm{mg} / \mathrm{g}$ TS in the late stage of the experiment.

$\mathrm{H} 2$ concentration in the gas phase did not exceed $0.04 \%$, which indicated the absence of inhibition of hydrogen consumers, i.e., hydrogenotrophic methanogens and/or homoacetogenic bacteria.

\subsubsection{PAM Biodegradability}

PAM biodegradability was tested by adding different concentrations of the PAM to digested sludge (inoculum) with subsequent anaerobic incubation of the mixtures (series B). The results are presented in Figure $1 \mathrm{~b}$ and Table 2.

Table 2. Characteristics of the process in the course of batch incubation of the mixture of digested sludge with different concentrations of the polyacrylamide flocculant as a substrate.

\begin{tabular}{|c|c|c|c|c|c|c|c|c|}
\hline \multirow[b]{2}{*}{ Sample } & \multirow{2}{*}{$\begin{array}{c}\text { Day of } \\
\text { Incubation }\end{array}$} & \multicolumn{4}{|c|}{ Volatile Fatty Acids Concentration } & \multirow{2}{*}{$\begin{array}{c}\text { Ammonium } \\
\text { Concentration, } \\
\text { mg/L }\end{array}$} & \multirow{2}{*}{$\begin{array}{c}\text { Methane } \\
\text { Content in } \\
\text { Biogas, \% }\end{array}$} & \multirow{2}{*}{$\begin{array}{l}\text { Methane } \\
\text { Yield, mL }\end{array}$} \\
\hline & & $\begin{array}{l}\text { Acetate, } \\
\mathrm{mmol} / \mathrm{L}\end{array}$ & $\begin{array}{c}\text { Propionate, } \\
\mathrm{mmol} / \mathrm{L}\end{array}$ & $\begin{array}{l}\text { Butyrate, } \\
\text { mmol/L }\end{array}$ & $\begin{array}{l}\text { Total VFA, } \\
\text { g/L }\end{array}$ & & & \\
\hline \multirow{4}{*}{$\begin{array}{c}\text { Control } \\
\text { (B-0) }\end{array}$} & 0 & 0.121 & 0.009 & 0.008 & 0.01 & 35.2 & 0 & 0 \\
\hline & 6 & 0.175 & 0.011 & 0.032 & 0.01 & 72.1 & 67.54 & 8.53 \\
\hline & 22 & 0.203 & 0.240 & 0.012 & 0.03 & - & 68.77 & 17.25 \\
\hline & 42 & 0.176 & 0.042 & 0.015 & 0.01 & 95.8 & 37.33 & 20.54 \\
\hline \multirow{4}{*}{ B-5 } & 0 & 0.121 & 0.009 & 0.008 & 0.01 & 35.2 & 0 & 0 \\
\hline & 6 & 0.169 & 0.021 & 0.032 & 0.01 & 92.3 & 66.10 & 8.58 \\
\hline & 22 & 0.351 & 0.062 & 0.054 & 0.03 & - & 69.79 & 16.57 \\
\hline & 42 & 0.224 & 0.009 & 0.013 & 0.01 & 104.5 & 37.67 & 19.95 \\
\hline \multirow{4}{*}{ B-40 } & 0 & 0.121 & 0.009 & 0.008 & 0.01 & 35.2 & 0 & 0 \\
\hline & 6 & 0.142 & 0.047 & 0.014 & 0.01 & 55.1 & 64.14 & 7.01 \\
\hline & 22 & 0.429 & 0.015 & 0.042 & 0.03 & - & 68.05 & 14.57 \\
\hline & 42 & 0.154 & 0.011 & 0.008 & 0.01 & 106.1 & 38.12 & 17.67 \\
\hline \multirow{4}{*}{ B-80 } & 0 & 0.121 & 0.009 & 0.008 & 0.01 & 35.2 & 0 & 0 \\
\hline & 6 & 0.179 & 0.116 & 0.019 & 0.02 & 83.2 & 66.09 & 7.6 \\
\hline & 22 & 0.556 & 0.018 & 0.037 & 0.04 & - & 68.98 & 14.87 \\
\hline & 42 & 0.171 & 0.020 & 0.007 & 0.01 & 109.4 & 35.84 & 17.81 \\
\hline \multirow{4}{*}{ B-200 } & 0 & 0.121 & 0.009 & 0.008 & 0.01 & 35.2 & 0 & 0 \\
\hline & 6 & 0.803 & 0.327 & 0.078 & 0.08 & 112.1 & 67.96 & 8.74 \\
\hline & 22 & 0.158 & 0.020 & 0.047 & 0.01 & - & 66.45 & 17.97 \\
\hline & 42 & 0.128 & 0.011 & 0.013 & 0.01 & 127.1 & 38.05 & 21.24 \\
\hline \multirow{4}{*}{ B-400 } & 0 & 0.121 & 0.009 & 0.008 & 0.01 & 35.2 & 0 & 0 \\
\hline & 6 & 1.221 & 0.313 & 0.071 & 0.09 & 125.3 & 50.99 & 5.15 \\
\hline & 22 & 0.689 & 0.362 & 0.029 & 0.07 & - & 74.84 & 15.65 \\
\hline & 42 & 0.141 & 0.078 & 0.009 & 0.01 & 137.4 & 23.71 & 19.67 \\
\hline
\end{tabular}

VFA-volatile fatty acids.

Increasing the PAMt amount resulted in a decreased specific methane yield per flocculant VS (Figure 1b). This was an indication that the PAM organic matter was not degraded directly to methane. However, signs of partial degradation of PAM were found. Formation of VFA, primarily acetate, was observed in all samples. The acids were mainly produced in the course of degradation of organic matter of the digested sludge used as the inoculum. A certain amount of the organic acids resulted from PAM degradation, as was indicated by increased amounts of acetate produced in the samples with higher PAM concentrations. Higher concentrations of ammonium nitrogen were observed in the flocculant-containing samples by the end of the experiment. Ammonium nitrogen could be released during the 
cleavage of nitrogen-containing groups of PAM molecules. H2 concentration in the gas phase did not exceed $0.044 \%$.

A correlation was observed between the size of the floccules formed in the presence of PAM and the flocculant concentration: larger floccules were formed at higher flocculant concentrations. Gradual floccules decomposition was observed in the course of the experiment, which led to an acceleration of the processes of microbial decomposition of VS during the experiment.

\subsection{Application of the Flocculant to Restore Methanogenesis in Destabilized Bioreactors}

In our previous experiments [16], it was shown that the maximum concentration of PAM (40 g/ kg TS) can contribute to the maintenance of methanogenesis in experimental reactors with a high organic load. To confirm the possibility of applying enforced flocculation caused by the PAM flocculant to restore methanogenesis, a model of a destabilized reactor was developed. Digestion was carried out at a lower inoculum-to-substrate ratio (ISR, 30\%/70\% based on total VS in the digesting mixture), elevated concentration of easily degradable s-OFMSW (45\%), lowered moisture content ( 92\%) and high VS concentration in the mixture $(40 \mathrm{~g} / \mathrm{kg})$.

On days 3-6 of the experiment, evidence of destabilization of AD due to substrate overloading was observed. During the first few days, significant amounts of hydrogen were accumulated (up to $17.2 \pm 4.7 \%$ of the gas phase volume). VFA, especially acetate, were produced and accumulated; acetate concentration increased 4.2-6.0 times over three days. The overall VFA concentration remained relatively low, $3.42 \pm 0.05 \mathrm{~g} / \mathrm{L}$. In all samples, $\mathrm{pH}$ decreased from 7.2 at the beginning of the experiment to $5.8 \pm 0.3$ after 3-6 days. A combination of these factors resulted in complete suppression of methane production by day 6 of the experiment.

On day 7, the PAM solution was added (the control samples were supplemented with the same volume of distilled water). The humidity of the mixture increased from $92.1 \pm$ $0.2 \%$ to $93.9 \pm 0.1 \%$. The experimental samples were then subdivided into two groups so that digestion was carried out either without or with mixing (shaking at $100 \mathrm{rpm}$ ).

Positive dynamics of methane accumulation and a decrease in the VFA concentration were observed only in the non-mixing samples. The samples treated with the PAM at $20 \mathrm{mg} / \mathrm{g}$ TS exhibited restoration of methanogenesis after acidification-caused destabilization after $4-5$ days. While insignificant positive changes were observed in PAM-40 samples 8 days after the flocculant treatment, a significant shift occurred only after 45 days.

Dynamics of methane accumulation in non-mixing samples and dynamics of VFA and hydrogen accumulation and consumption are shown in Figure 2a,b and Figure 3, respectively. The process characteristics are presented in Table 3.

Table 3. Characteristics of the process of anaerobic digestion in the non-mixing mixtures.

\begin{tabular}{|c|c|c|c|c|c|c|c|}
\hline \multirow{2}{*}{$\begin{array}{c}\text { The Concentration of } \\
\text { PAM in the Experimental } \\
\text { Mixture }\end{array}$} & \multicolumn{2}{|c|}{ VFA Concentration, $\mathrm{g} / \mathrm{L}$} & \multicolumn{2}{|c|}{$\begin{array}{l}\text { Ammonium Concentration, } \\
\mathrm{mg} / \mathrm{L}\end{array}$} & \multirow{2}{*}{$\mathrm{pH}$} & \multirow{2}{*}{$\begin{array}{l}\text { Methane } \\
\text { Yield, mL/g } \\
\text { VS }_{\text {initial }}\end{array}$} & \multirow{2}{*}{$\begin{array}{l}\text { VS Decom- } \\
\text { position, } \\
\%\end{array}$} \\
\hline & Initial & Terminal & Initial & Terminal & & & \\
\hline Control (PAM-0) & $2.23 \pm 0.11$ & $11.75 \pm 0.58$ & $60.7 \pm 3.0$ & $822.1 \pm 41.1$ & 5.68 & $11.16 \pm 0.55$ & $35.0 \pm 1.7$ \\
\hline PAM-20 & $2.23 \pm 0.11$ & $0.73 \pm 0.03$ & $60.7 \pm 3.0$ & $1047.2 \pm 52.3$ & 7.60 & $189.84 \pm 9.54$ & $60.4 \pm 3.0$ \\
\hline PAM-40 & $2.23 \pm 0.11$ & $8.37 \pm 0.41$ & $60.7 \pm 3.0$ & $1033.0 \pm 51.6$ & 6.89 & $53.41 \pm 2.67$ & $52.6 \pm 2.6$ \\
\hline PAM-60 & $2.23 \pm 0.11$ & $13.09 \pm 0.65$ & $60.7 \pm 3.0$ & $836.5 \pm 41.8$ & 5.96 & $12.45 \pm 0.62$ & $52.1 \pm 2.6$ \\
\hline
\end{tabular}

PAM—polyacrylamide, VFA—volatile fatty acids, VS—volatile solids. 

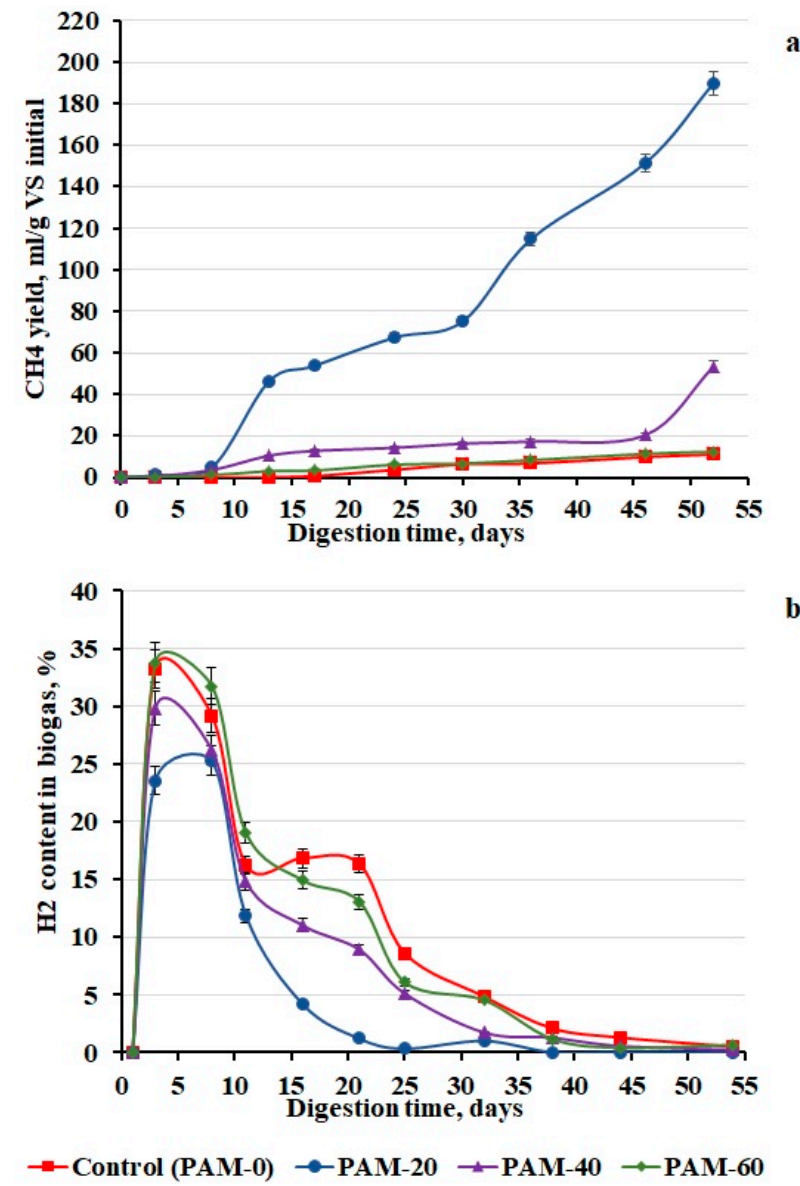

Figure 2. Dynamics of methane accumulation (ml/g VS initial) (a) and hydrogen content (\%) (b) in biogas in bioreactors destabilized due to accumulation of high volatile fatty acid (VFA) concentrations operated without mixing after addition of different polyacrylamide (PAM) concentrations for the restoration of methanogenesis: Control (PAM-0) without the flocculant; PAM-20, PAM-40, and PAM60 , the flocculant concentrations 20,40, and $60 \mathrm{mg} / \mathrm{g}$ TS, respectively. The X-axis begins (0 days) on day 7 of the experiment when the flocculant was added.

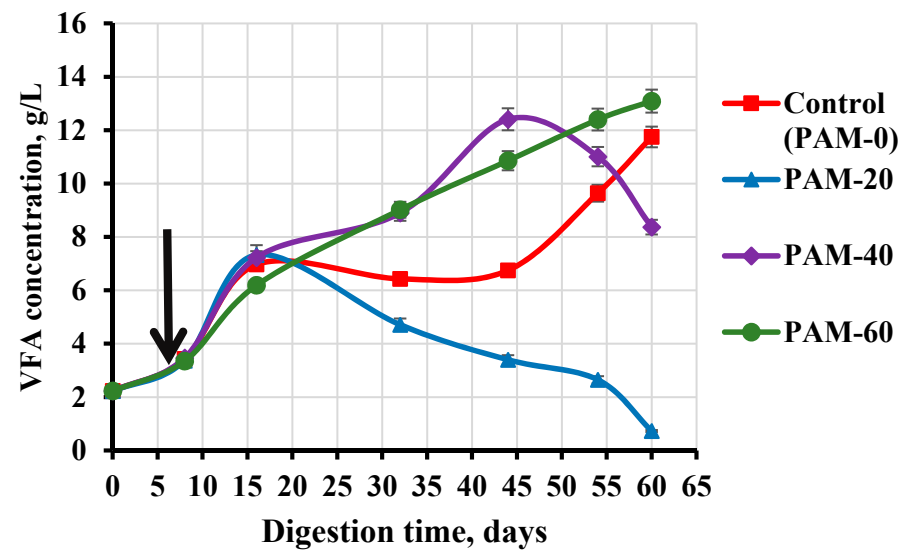

Figure 3. Dynamics of volatile fatty acids (VFA) accumulation and consumption (overall concentrations of acetate, propionate, and butyrate, g/L): Control (polyacrylamide (PAM)-0) without the flocculant; PAM-20, PAM-40, and PAM-60, the flocculant concentrations 20, 40, and $60 \mathrm{mg} / \mathrm{g}$ total solids (TS), respectively. Time of the flocculant addition is indicated by the arrow. 
A correlation between the time of methanogenesis activation and the beginning of a decrease in the VFA concentration may be seen in Figures 2 and 3. In the PAM-20 mixtures, the VFA concentration peaked and began to decrease 5-7 days after the flocculant addition, which corresponded to the onset of methane accumulation in the gas phase. Similar changes were observed in the PAM-40 mixtures after 40 days of the experiment. VFA consumption resulted in a $\mathrm{pH}$ shift to more neutral values (Table 3). However, only in the PAM-20 samples, the $\mathrm{pH}$ reached the optimal values by the end of the experiment. In the PAM- 60 mixtures and the control (without PAM), the total VFA concentration increased until the end of the experiment. While the average concentrations of propionate $(22.4$ and $23.0 \mathrm{mM})$ and butyrate (70.4 and $73.4 \mathrm{mM}$ ) in the control and the PAM-60 samples were similar, acetate concentration in PAM-60 exceeded the value for the control by $17.5 \pm 1.9 \mathrm{mM}$. Increased acetate concentration was probably due to a partial restoration of the activity of fermenting, homoacetogenic and syntrophic bacteria or partial degradation of PAM followed by acetate production. Hydrogen ratio in biogas reached a maximum on day 3 of incubation and then was gradually declining till the end of the experiment. Active hydrogen production attributes to active hydrolysis and fermentation in the samples. Coincidently, it reveals that the activity of hydrogenotrophic methanogens was not sufficient or was inhibited.

The concentration of total ammonia nitrogen (TAN) produced during digestion did not exceed $1.1 \mathrm{~g} / \mathrm{L}$, with the highest values in the samples PAM-20 and PAM-40 (Table 3). Increasing TAN concentration indicated the hydrolysis of proteins and nucleic acids. Lower TAN concentrations in the PAM-60 samples resulted probably from suppression of the microbial community, including the decreased activity of proteolytic bacteria. Another possible reason may be a decreased rate of PAM decomposition under destabilized conditions or at concentrations above $40 \mathrm{~g} / \mathrm{kg}$ TS. Reduced bioavailability of proteins after PAM addition also might account for lower TAN concentration [17]. The degree of TS degradation determined using the standard methods [16] was $20.1 \%$ for the control and 45.3, 38.5, and 36.5\% for the mixtures PAM-20, PAM-40, and PAM-60, respectively. The degree of VS degradation varied from 35 to $60.4 \%$ depending on the amount of added PAM (Table 3). It should be noted that the products of decomposition of organic matter from the substrates were not converted to biogas completely. Thus, in the control mixtures VS degradation resulted in the formation of VFA, ethanol, and other fermentation products, while no further conversion of these compounds to methane occurred due to suppressed activity of syntrophic bacteria and methanogenic archaea.

Methanogenesis was not restored in the mixing samples. In all samples hydrogen was accumulated to 35.9-40.3\% 7 days after the PAM addition; by the end of the experiment, its concentration decreased to $12.6-25.5 \%$. The lowest hydrogen concentration in the gas phase was observed for the PAM-20 samples. High hydrogen concentrations in the gas phase indicated destabilization of the AD process; it also suppressed the activity of syntrophic bacteria involved in VFA utilization [20,21]. Thus, VFA accumulated, and their concentration by the end of the experiment was as high as $9.54 \pm 0.15 \mathrm{~g} / \mathrm{L}$. It should be noted that VFA accumulation in mixing samples occurred slower than in non-mixing samples, and VFA concentrations did not reach the maxima observed for digestion without mixing (12.4-13.1 g/L). This was probably due to considerable inhibition of all anaerobic processes, including acidogenesis. The TAN content in all mixtures was 1039-1083 mg $\mathrm{N}-\mathrm{NH} 4 / 1$, independent on the amount of PAM added. The degree of VS decomposition in the course of digestion was $\sim 40$ to $45 \%$.

The floccules size and the duration of their existence were shown to be of critical importance for the restoration of methanogenesis. The results of the granulometric analysis of the samples of the digested mass collected by the end of the experiment are presented in Figure 4. Both in the control samples and in all samples before the PAM addition, particles smaller than $50 \mu \mathrm{m}$ in diameter constituted $51.5 \pm 0.4 \%$, while $28.8 \pm 1.3 \%$ had a diameter of 50-100 $\mu \mathrm{m}$. No particles over $300 \mu \mathrm{m}$ were present. In PAM-treated samples incubated without mixing, $91.3-99.8 \%$ of the particles were from 100 to $700 \mu \mathrm{m}$ in diameter. 

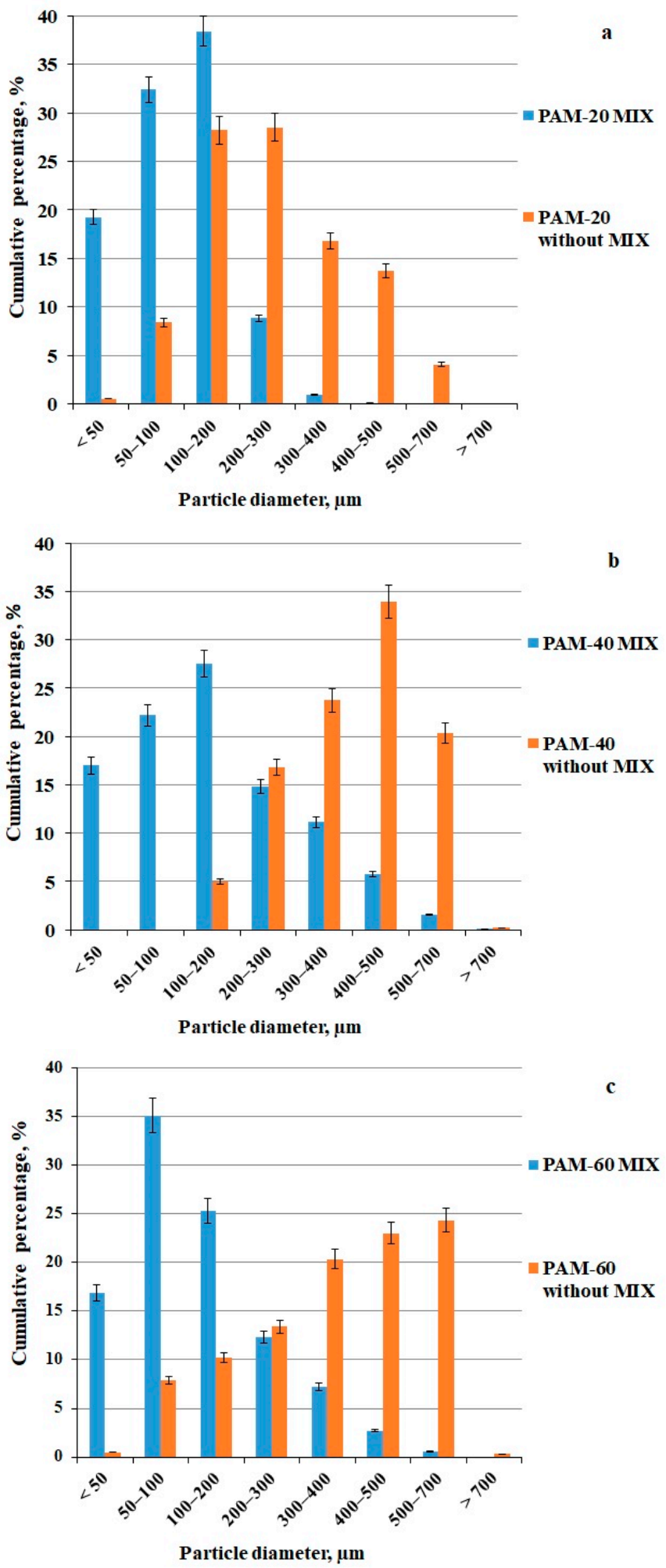

Figure 4. Floccules size in the samples treated with 20 (a), 40 (b), and 60 (c) mg polyacrylamide (PAM)/g total solids (TS) and incubated with and without mixing, at the end of the experiment.

In mixing mixtures, floccules break-up was more rapid, and by the end of the experiment 39.2-51.9\% were smaller than $100 \mu \mathrm{m}$. 


\section{Discussion}

\subsection{Toxicity of the PAM and its Possible Degradation under Anaerobic Conditions}

In a number of works, low direct toxicity of PAM-based flocculants for anaerobic microorganisms was reported [13,22]. Our experiments showed that all tested PAM concentrations caused a decrease in the initial methanogenesis rate. However, even the extremely high flocculant concentration of $400 \mathrm{mg} / \mathrm{g}$ TS did not inhibit AD completely. This data confirm the results obtained by other researchers, who did not observe the toxicity of PAM flocculants under mesophilic conditions at concentrations of 105 and $415 \mathrm{mg} / \mathrm{g}$ TS [13,20].

Nevertheless, clear patterns of partial inhibition of the anaerobic microbial community by the PAM were found. Increasing the flocculant amount resulted in a decreased specific methane yield per flocculant VS (Figure 1b). This was an indication that the PAM organic matter was not degraded directly to methane. Our data confirm the results by Song et al., who found that only partial PAM degradation occurred under anaerobic conditions at 35 and $55{ }^{\circ} \mathrm{C}$, resulting in decreased PAM molecular mass due to partial hydrolysis and in the removal of amide groups. The authors showed that internal $\mathrm{C}-\mathrm{C}$ bonds in the PAM molecule were to a considerable degree resistant to microbial hydrolysis [23].

The intrinsic inhibitory effect of PAM is associated with the disruption of the processes of biopolymer hydrolysis. PAM limits the availability of waste VS for exposure to microbial enzymes. At elevated PAM concentrations in the medium, hydrolysis of both the waste VS and of the polyacrylamide molecule is probably decelerating [18]. PAM has the most pronounced inhibitory effect on the enzymatic activity of hydrolases [24]. PAM can form a covalent bond and sweep flocculation between cationic PAM and the enzymes, significantly reducing their activity [24]. In addition, some ectoenzymes could be used for degradation of both organics and PAM due to the similar functional groups between them, which can also contribute to a decrease in the efficiency of degradation of the main substrate [24,25].

The observed decrease in the rates of methanogenesis and the efficiency of the process of anaerobic transformation of VS can also be associated with the toxic effect of PAM decomposition products on anaerobic microorganisms. It is known that the main products of PAM decomposition under anaerobic condition are polyacrylic and acrylic acids, the proportion of which is about $50 \%$ of all products formed $[17,18,25]$. While acrylamide and acrylic acid suppress the activity of methanogenic archaea, polyacrylic acid affects both methanogens and hydrolytic and syntrophic bacteria, as well as homoacetogenic bacteria $[17,24]$. At the same time, acrylic acid has no significant effect on hydrolytic processes. PAM also has a pronounced inhibitory effect on acidogenesis [24].

Our data show that high concentrations of the PAM had the most significant inhibitory effect on syntrophic bacteria involved in VFA conversion, primarily on the propionateoxidizing syntrophic bacteria. The concentration of PAM 80-200 g/ $\mathrm{kg}$ TS led to a decrease in the efficiency of consumption of propionate by $41-49 \%$, while the maximum concentration of PAM completely inhibited the decomposition of propionate. It is well known that the accumulation of propionate is one of the important signs indicating the destabilization of the AD process [26]. We also observed the accumulation and slower degradation of acetate in the samples treated with 80-400 mg PAM/g TS, which indicate the inhibitory effect of PAM or its degradation products on acetate-utilizing methanogens. The sensitivity of acetoclastic methanogens to PAM and its degradation products has been previously shown by Wang et al. [17].

We observed signs of partial degradation of PAM, including an increase in total VFA concentration and total ammonium nitrogen concentration. Formation of VFA, primarily acetate, was observed in all samples, both in the T and B series. The acids were mainly produced in the course of degradation of organic matter of the digested sludge used as the inoculum. A certain amount of organic acids resulted from PAM degradation, as was indicated by increased amounts of acetate produced in the samples with higher PAM concentrations. Partial PAM hydrolysis and conversion of the intermediate products of PAM decomposition to acetate is another possible cause for acetate accumulation in the flocculant-treated samples [25]. Thus, Dai et al. showed polyacrylic acid to be the main 
source for acetate formation during PAM degradation [25]. Acetate was also a major product of mesophilic AD of SS treated with different concentrations of PAM, and its amount increased with increasing PAM concentration [24].

Increases in the concentrations of ammonium nitrogen were observed in the flocculantcontaining samples rather than in the control ones, indicating partial PAM degradation (removal of amide side groups). Similar experiments by Wang et al. revealed that the cationic PAM promoted the release of ammonium nitrogen from SS [17]. Dai et al. found that increasing PAM concentration in the medium resulted in the formation of a lower specific amount of ammonium nitrogen (mg N-NH4/g PAM) [18]. A similar tendency was observed in our experiments.

Our data indicated that the PAM was partially biodegraded even at its highest tested concentration of $400 \mathrm{mg} / \mathrm{g}$ TS. These results do not agree with the observations of Dai et al., who found that while biological PAM hydrolysis occurred at its concentrations of 100-200 mg/L, its efficiency decreased drastically at PAM concentrations above 300 $\mathrm{mg} / \mathrm{L}$ [25]. In our experiments, PAM concentration was $37 \mathrm{mg} / \mathrm{L}$ in B-5 samples and 296-2964 mg/L in other samples. However, PAM mineralization (stepwise degradation up to methane formation) did not occur. The degradation was limited to the formation of various intermediate products, as well as detachment of nitrogen-containing side groups (the latter resulted in the accumulation of ammonium nitrogen).

The possibility of partial PAM biodegradation under anaerobic conditions was reported in several works $[17,18,23]$. In the absence of alternative substrates, microorganisms can use PAM as a source of nitrogen and even of carbon $[18,25,27]$. Wang et al. showed that PAM is relatively resistant to anaerobic degradation compared to polysaccharides and proteins and therefore is used at the later stages when other substrates are available [17]. Thermophilic conditions $\left(50-55^{\circ} \mathrm{C}\right)$ promote partial PAM depolymerization, which increases its availability to microorganisms and the degree of its biodegradation [23]. The polymeric structure of PAM and its high molecular mass, as well as resistance of the floccules to hydrolases, are the main factors determining PAM resistance to microbial degradation $[22,28]$.

A correlation was observed between the size of the floccules formed in the presence of PAM and the flocculant concentration: larger floccules were formed at higher flocculant concentrations. A similar correlation was reported by other authors [16-18]. The size of floccules can also affect the efficiency of hydrolysis processes and slow down the conversion of the products of partial decomposition of VS into methane, which is reflected in a decrease in the rate of methanogenesis.

\subsection{Application of the Flocculant to Restore Methanogenesis in Destabilized Bioreactors}

PAM-based flocculant was effective for methanogenesis restoration in thermophilic bioreactors destabilized due to accumulation of high VFA concentrations only in nonmixing samples. The most effective recovery of methanogenesis was observed at a concentration of $20 \mathrm{mg} / \mathrm{g}$ TS. Methanogenesis was not restored in the samples digested under mixing. In all samples, hydrogen was accumulated in the gas phase, which indicated destabilization of the AD.

Most likely, forced flocculation and long-term preservation of floccules was the main reason for the restoration of methanogenesis in destabilized bioreactors.

During the experiment, a multidirectional effect of several factors was observed. Based on the results obtained, excessive VFA accumulation is a more significant factor inhibiting the $\mathrm{AD}$ process. In this case, the addition of a flocculant has a less inhibitory effect. In previous studies with vigorous mixing and increasing the organic loading rate to $7.6-9.4 \mathrm{~kg}$ $\mathrm{VS} /\left(\mathrm{m}^{3}\right.$ day), an excessive accumulation of VFA was observed, mainly acetate (up to $14 \mathrm{~g} / \mathrm{L}$ ) and propionate (up to $4 \mathrm{~g} / \mathrm{L}$ ) [29]. Minimal mixing promotes the initiation of methanogenic centers [30]. Intense mixing leads to the distribution of the VFA formed in large quantities throughout the entire volume of the digested mass, which can inhibit syntrophic bacteria and methanogenic archaea $[29,30]$. 
In agitated mixtures, floccules break-up was more rapid, and by the end of the experiment 39.2-51.9\% were smaller than $100 \mu \mathrm{m}$. This is in accordance with the data of Bolzonella et al., who found that continuous agitation of digested mass promoted more rapid break-up of the flocculant-induced floccules [31].

Thus, to achieve the positive effect of enforced flocculation, mixing of the digested mixture should be stopped or decreased to a minimum in order to extend the duration of floccules existence and to avoid their untimely disintegration.

Application of PAM concentrations higher than $20 \mathrm{~g} / \mathrm{kg}$ TS is probably less efficient due to the inhibitory properties of the flocculant.

Our experiments revealed that $\mathrm{pH}$ decrease caused by excessive VFA accumulation did not affect flocculation. These results are in agreement with those of El-Mamouni et al., who showed that the efficiency of PAM-induced floccules formation did not change at $\mathrm{pH}$ decrease [32]. According to Dai et al., the size of PAM-induced floccules depended on an ambient $\mathrm{pH}$ : the largest floccules were formed at neutral $\mathrm{pH}(7.0)$ and $\mathrm{pH}$ decrease to 4.0, while the floccules size decreased at $\mathrm{pH}$ above 8.0 [25]. This finding is important for PAM application for the restoration of methanogenesis in reactors destabilized due to VFA accumulation. The larger the floccules size, the higher the probability of the positive effect of the flocculant and the rate of the process restoration.

Most of the authors investigating the effect of flocculants on anaerobic digestion agreed that flocculant treatment of SS results in lower mass transfer efficiency and slower hydrolysis [13,16-18]. Partial limitation of substrate availability for hydrolysis, which is a result of flocculation, is among the most probable mechanisms of the restorative effect of the flocculant. This decreases the rates of hydrolytic processes and the rate of VFA accumulation in the medium. Wang et al. showed that as a result of PAM addition (3-24 $\mathrm{mg} / \mathrm{g}$ TS) the concentrations of soluble proteins and polysaccharides decreased by $23-67 \%$, depending on the PAM concentration. It also affected their subsequent release from the floccules [17].

Formation of microniches within the floccules is another possible mechanism. The activity of syntrophic bacteria and methanogenic archaea, which are highly sensitive to variations of $\mathrm{pH}$ and hydrogen and VFA concentrations in the medium is preserved in these microniches. Outer layers of the floccules may act as a protective barrier, which impaired mass transfer of metabolites into its inner zones. This suggestion is indirectly confirmed by the fact that methanogenesis was restored only in the samples which were not mixed and in which large floccula were therefore preserved. A positive effect of enforced biomass aggregation caused by the PAM flocculant on methanogenic activity, similar to that of natural aggregation, was shown by El-Mamouni et al. [32]. The authors suggested that this effect was caused by closer proximity and interaction of acetogenic bacteria and methanogenic archaea resulting in accelerated consumption of acetate and $\mathrm{H}_{2}$ [32].

\section{Conclusions}

Our experiments showed that partial microbial degradation of the polyacrylamide flocculant occurred in the course of thermophilic anaerobic digestion, although complete PAM mineralization did not occur.

The addition of the flocculant (5 to $400 \mathrm{mg} / \mathrm{g}$ TS) resulted in a decrease in the initial methanogenesis rate when VFA were used as substrates. However, anaerobic degradation of organic matter was not inhibited completely even by the highest tested flocculant concentration (400 mg/g TS). Impaired biopolymer hydrolysis and negative effect on syntrophic bacteria (especially on propionate oxidizers) are the most probable mechanisms of inhibition.

At $20 \mathrm{mg} / \mathrm{g}$ TS, the PAM flocculant may be used to restore methanogenesis in bioreactors destabilized by the accumulation of high VFA concentration. The features required for methanogenesis restoration after the flocculant addition are large floccules size and the absence of agitation in order to provide for the long-term existence of the flocculantinduced floccules. 
Author Contributions: Conceptualization, A.A.N. and Y.V.L.; methodology, A.A.N.; software, V.P.; validation, A.A.E.; formal analysis, E.A.Z.; investigation, A.A.N., A.A.E., and Y.V.L.; resources, A.A.K. and D.A.K.; data curation, A.A.N.; writing-original draft preparation, A.A.N.; writing-review and editing, A.A.N. and Y.V.L.; visualization, A.A.N. and A.A.K.; supervision, A.A.N. and Y.V.L.; project administration, A.A.N. and Y.V.L.; funding acquisition, Y.V.L. All authors have read and agreed to the published version of the manuscript.

Funding: This work was partially supported by the Federal State Budgetary Institution "Russian Foundation for Basic Research" as part of scientific project No. 18-29-25042.

Conflicts of Interest: The authors declare no conflict of interest.

\section{References}

1. Werle, S.; Sobek, S. Gasification of sewage sludge within a circular economy perspective: A Polish case study. Environ. Sci. Pollut. Res. 2019, 26, 35422-35432. [CrossRef]

2. Yadav, P.; Samadder, S.R. A global prospective of income distribution and its effect on life cycle assessment of municipal solid waste management: A review. Environ. Sci. Pollut. Res. 2017, 24, 9123-9141. [CrossRef]

3. Khalid, A.; Arshad, M.; Anjum, M.; Mahmood, T.; Dawson, L. The anaerobic digestion of solid organic waste. Waste Manag. 2011, 31, 1737-1744. [CrossRef]

4. Bolzonella, D.; Battistoni, P.; Susinii, C.; Cecchi, F. Anaerobic codigestion of waste activated sludge and OFMSW: The experiences of viareggio and treviso plants (Italy). Water Sci. Technol. 2006, 53, 203-211. [CrossRef]

5. Stams, A.J.; Sousa, D.Z.; Kleerebezem, R.; Plugge, C.M. Role of syntrophic microbial communities in high-rate methanogenic bioreactors. Water Sci. Technol. 2012, 66, 352-362. [CrossRef]

6. Schnürer, A. Biogas production: Microbiology and technology. In Anaerobes in Biotechnology: Advances in Biochemical Engineering/Biotechnology; Hatti-Kaul, R., Mamo, G., Mattiasson, B., Eds.; Springer: Cham, Switzerland, 2016; Volume 156. [CrossRef]

7. Mata-Alvarez, J.; Dosta, J.; Macé, S.; Astals, S. Codigestion of solid wastes: A review of its uses and perspectives including modeling. Crit. Rev. Biotechnol. 2011, 31, 99-111. [CrossRef]

8. Schnurer, A.; Jarvis, A. Microbiological Handbook for Biogas Plant; Swedish Waste Management U2009:03; Swedish Gas Centre Report 207; Swedish Gas Centre: Malmö, Sweden, 2010; p. 138.

9. Fotidis, I.A.; Karakashev, D.; Angelidaki, I. Bioaugmentation with an acetate-oxidising consortium as a tool to tackle ammonia inhibition of anaerobic digestion. Bioresour. Technol. 2013, 146, 57-62. [CrossRef]

10. Water Environment Federation. Operation of Municipal Wastewater Treatment Plants: Manual of Practice No. 11, 6th ed.; Water Environment Federation: Alexandria, VA, USA, 2008; p. 1980.

11. Chen, Y.; Cheng, J.J.; Creamer, K.S. Inhibition of anaerobic digestion process: A review. Bioresour. Technol. 2008, 99, 40444064. [CrossRef]

12. Nikitina, A.A.; Kevbrina, M.V.; Kallistova, A.Y.; Nekrasova, V.K.; Litti, Y.V.; Nozhevnikova, A.N. Intensification of microbial decomposition of organic fraction of municipal waste: Laboratory and field experiments. Appl. Biochem. Microbiol. 2015, 51, 393-401. [CrossRef]

13. Campos, E.; Almirall, M.; Mtnez-Almela, J.; Palatsi, J.; Flotats, X. Feasibility study of the anaerobic digestion of dewatered pig slurry by means of polyacrylamide. Bioresour. Technol. 2008, 99, 387-395. [CrossRef]

14. Lee, C.S.; Robinson, J.; Chong, M.F. A review on application of flocculants in wastewater treatment. Process. Saf. Environ. Prot. 2014, 92, 489-508. [CrossRef]

15. Lu, L.; Pan, Z.; Hao, N.; Peng, W. A novel acrylamide-free flocculant and its application for sludge dewatering. Water Res. 2014, 57, 304-312. [CrossRef]

16. Litti, Y.; Nikitina, A.; Kovalev, D.; Ermoshin, A.; Mahajan, R.; Goel, G.; Nozhevnikova, A. Influence of cationic polyacrilamide flocculant on high-solids' anaerobic digestion of sewage sludge under thermophilic conditions. Environ. Technol. 2019, 40, 1146-1155. [CrossRef]

17. Wang, D.; Liu, X.; Zeng, G.; Zhao, J.; Liu, Y.; Wang, Q.; Chen, F.; Li, X.; Yang, Q. Understanding the impact of cationic polyacrylamide on anaerobic digestion of waste activated sludge. Water Res. 2018, 130, 281-290. [CrossRef]

18. Dai, X.; Luo, F.; Yi, J.; He, Q.; Dong, B. Biodegradation of polyacrylamide by anaerobic digestion under mesophilic condition and its performance in actual dewatered sludge system. Bioresour. Technol. 2014, 153, 55-61. [CrossRef]

19. Pfennig, N. Anreicherungskulturen für rote und grüne Schwefelbakterien. Zbl. Bakt. I. Abt. Orig. Suppl. 1965, 1, 179-189.

20. Appels, L.; Baeyens, J.; Degrève, J.; Dewil, R. Principles and potential of the anaerobic digestion of waste-activated sludge. Prog. Energy Combust. Sci. 2008, 34, 755-781. [CrossRef]

21. McInerney, M.J.; Sieber, J.R.; Gunsalus, R.P. Syntrophy in anaerobic global carbon cycles. Curr. Opin. Biotechnol. 2009, 20, 623-632. [CrossRef]

22. Chu, C.P.; Lee, D.J.; Chang, B.V.; You, C.H.; Liao, C.S.; Tay, J.H. Anaerobic digestion of polyelectrolyte flocculated waste activated sludge. Chemosphere 2003, 53, 757-764. [CrossRef]

23. Song, W.; Zhang, Y.; Gao, Y.; Chen, D.; Yang, M. Cleavage of the main carbon chain backbone of high molecular weight polyacrylamide by aerobic and anaerobic biological treatment. Chemosphere 2017, 189, 277-283. [CrossRef] 
24. Liu, X.; Xu, Q.; Wang, D.; Wu, Y.; Yang, Q.; Liu, Y.; Wang, Q.; Li, X.; Li, H.; Zeng, G.; et al. Unveiling the mechanisms of how cationic polyacrylamide affects short-chain fatty acids accumulation during long-term anaerobic fermentation of waste activated sludge. Water Res. 2019, 155, 142-151. [CrossRef]

25. Dai, X.; Luo, F.; Zhang, D.; Dai, L.; Chen, Y.; Dong, B. Waste-activated sludge fermentation for polyacrylamide biodegradation improved by anaerobic hydrolysis and key microorganisms involved in biological polyacrylamide removal. Sci. Rep. 2015, 5 , 11675. [CrossRef]

26. Pullammanappallil, P.C.; Chynoweth, D.P.; Lyberatos, G.; Sveronos, S.A. Stable performance of anaerobic digestion in the presence of a high concentration of propionicacid. Bioresour. Technol. 2001, 78, 165-169. [CrossRef]

27. Kay-Shoemake, J.L.; Watwood, M.E.; Lentz, R.D.; Sojka, R.E. Polyacrylamide as an organic nitrogen source for soil microorganisms with potential effects on inorganic soil nitrogen in agricultural soil. Soil Biol. Biochem. 1998, 30, 1045-1052. [CrossRef]

28. El-Mamouni, R.; Frigon, J.C.; Hawari, J.; Marroni, D.; Guiot, S.R. Combining photolysis and bioprocesses for mineralization of high molecular weight polyacrylamides. Biodegradation 2002, 13, 221-227. [CrossRef]

29. Stroot, P.G.; McMahon, K.D.; Mackie, R.I.; Raskin, L. Anaerobic codigestion of municipal solid waste and biosolids under various mixing conditions-I. digester performance. Water Res. 2001, 35, 1804-1816. [CrossRef]

30. Vavilin, V.A.; Angelidaki, I. Anaerobic degradation of solid material: Importance of initiation centers for methanogenesis, mixing intensity, and 2D distributed model. Biotechnol. Bioeng. 2004, 89, 113-122. [CrossRef]

31. Bolzonella, D.; Pavan, P.; Battistoni, P.; Cecchi, F. Influence of the cationic flocculant praestol K233L on the mesophilic anaerobic digestion of waste activated sludge. J. Residuals Sci. Technol. 2005, 2, 133-141. [CrossRef]

32. El-Mamouni, R.; Leduc, R.; Guiot, S.R. Influence of synthetic and natural polymers on anaerobic granulation process. Water Sci. Technol. 1998, 38, 341-347. [CrossRef] 